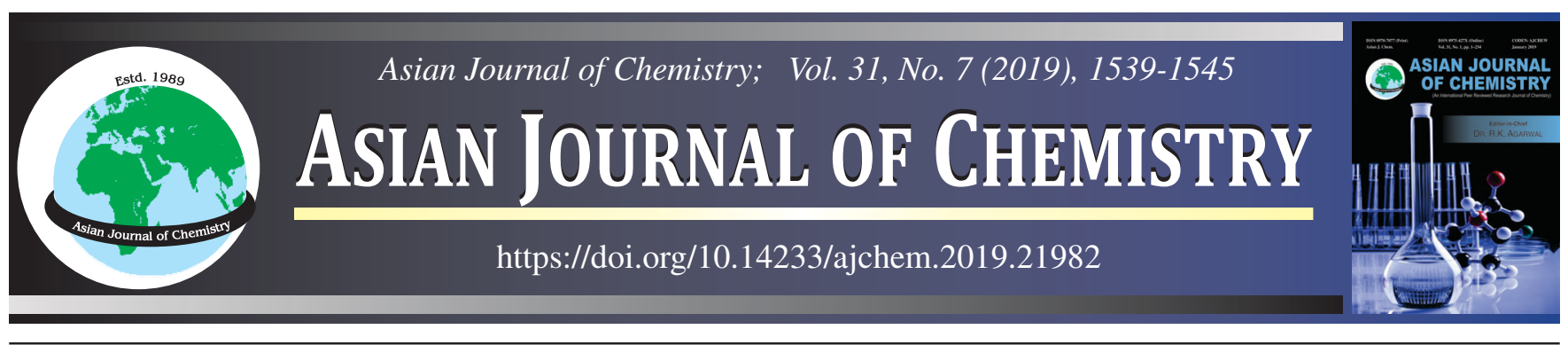

\title{
Development, Optimization and Validation of a Selective Stability Indicating RP-HPLC Method for Estimation of Glecaprevir and Pibrentasvir and Its Degradation Products Using Quality by Design Approach
}

\author{
C. VAnitha ${ }^{1,2}$, S.V. Satyanarayana ${ }^{3}$ and K. Bhaskar Reddy ${ }^{2, *}$
}

${ }^{1}$ Department of Pharmaceutical Sciences, Jawaharlal Nehru Technological University Anantapur, Ananthapuramu-515002, India ${ }^{2}$ Department of Pharmaceutics, Sri Venkateswara College of Pharmacy, Chittoor-517127, India

${ }^{3}$ Department of Chemical Engineering, Jawaharlal Nehru Technological University Anantapur, Ananthapuramu-515002, India

*Corresponding author: E-mail: bhaskurra@gmail.com

Received: 6 February 2019;

Accepted: 18 March 2019;

Published online: 21 May 2019;

AJC-19410

\begin{abstract}
The present work focused on QbD driven approach for the development, optimization of stability indicating method for glecaprevir and pibrentasvir in bulk drug and its degradation products. The chromatographic separation was performed on Hypersil $\mathrm{C}_{8}(150 \mathrm{~mm} \times 4.6,5$ $\mu$ ) with a flow rate of $1 \mathrm{~mL} / \mathrm{min}$ at $260 \mathrm{~nm}$. The mobile phase employed was sodium phosphate monobasic and monohydric buffer and acetonitrile (65:35) having $\mathrm{pH}$ of 4.2 at $30{ }^{\circ} \mathrm{C}$ of column temperature. The degradation studies were carried out for glecaprevir and pibrentasvir under the stress condition hydrolysis (acid, base and neutral), oxidation, photolytic and thermal as per ICH guidelines. In alkali degradation chromatogram, more number of degradant peaks was appeared along with the risk factor, selectivity of the method. The selectivity of the method was established by resolving the resolution of degradant peaks and retention time of drugs by the application of design of experiment. The interaction effect of factors of $\mathrm{pH}$ mobile phase, column temperature and \% mobile phase were studied through response surface method (RSM) and central composite design (CCD). The optimized selective method was established for the detection of glecaprevir and pibrentasvir along with degradant peaks by optimized conditions were proposed by the model. Then the optimized method was validated for the parameters like linearity, accuracy, precision and robustness as per ICH guidelines.
\end{abstract}

Keywords: Central composite design, Glecaprevir, Pibrentasvir, Stress degradation.

\section{INTRODUCTION}

Glecaprevir and pibrentasvir are the second generation direct acting antiviral drugs for HCV [1]. The non-structural (NS) protein 3/4A protease inhibitor, glecaprevir (ABT-493) is combined with HCV NS5A inhibitor, pibrentasvir (ABT 530) as fixed dosage form to treat HCV genotypes 1-6. This fixed dose combination has potent antiviral activity against all genotypes of hepatitis $\mathrm{C}$ viruses [2]. The proteolysis of $\mathrm{HCV}$ polyprotein is essential step for viral replication which is inhibited by glecaprevir. The NS5A is responsible for viral replication and virions assemble of virus which is inhibited by pibrentasvir [2]. In the literature few analytical methods has been reported like RP-HPLC methods [3-5], UPLC [6] method, Stability indicating assay methods $[7,8]$. The drug combination were newly introduced for the treatment of $\mathrm{HCV}$, so very few analytical basic methods were reported but till now none have reported on the estimation of glecaprevir and pibrentasvir stability by quality by design approach. The first report of this work will provide the complete profile of targeted drug, risk assessment aspects and comprehensive study of method variables and their interaction effect on response. The $\mathrm{QbD}$ approach absolutely overtook the disadvantages of traditional one factor changing method by providing the detailed interaction of multiple variables at a time on method response. It also provides a sound knowledge on understanding of method and product by the interaction and risk assessment [9-13].

Hence an attempt was made to develop simple, sensitive, precise, robust selective stability indicating RP-HPLC method was developed for the estimation of glecaprevir and pibrentasvir

This is an open access journal, and articles are distributed under the terms of the Creative Commons Attribution-NonCommercial-ShareAlike 4.0 (CC BY-NC-SA 4.0) International License which allows readers to freely read, download, copy, distribute, print, search, or link to the full texts of its articles and to use them for any other lawful non-commercial purpose as long as the original source is duly acknowledged. 
by $\mathrm{QbD}$ approach. The objective of study includes forced degradation of drugs as per ICH guidelines, preliminary selection of influencing variables using factorial design, comprehensive study of interaction of variables through statistical approaches, optimization of methods by desirability method and verification of the method followed by validation of method as per ICH guidelines.

\section{EXPERIMENTAL}

Distilled water (HPLC grade), acetonitrile (HPLC grade), sodium dihydrogen orthophosphate mono basic, orthophosphoric acid (AR grade) were purchased from Merck specialties private limited, Mumbai, India. The active pharmaceutical ingredient was purchased from MSN pharmaceuticals, Hyderabad.

Liquid chromatography comprised a binary solvent pump and photodiode-array detector used for separation (WATERS 2695) utilizing Empower-2 software for processing (Waters Corporation, Milford, MA, USA).

Design of expert software: The design expert software 11.0.5.0 free trial version was used to plan the experiment's design.

Chromatographic conditions: The chromatographic separation was performed on Hypersil $\mathrm{C}_{8}(150 \mathrm{~mm} \times 4.6,5 \mu)$ with a flow rate of $1 \mathrm{~mL} / \mathrm{min}$ at $260 \mathrm{~nm}$. The column temperature was maintained at $30{ }^{\circ} \mathrm{C}$. The mobile phase employed was sodium phosphate monobasic and monohydric buffer and acetonitrile (65:35) having $\mathrm{pH}$ of 4.2. The $\mathrm{pH}$ of buffer solution was adjusted with $0.1 \%$ orthophosphoric acid.

Stress degradation study: The drugs were treated with $0.1 \mathrm{~N} \mathrm{HCl}$ for $3 \mathrm{~h}$ at $80^{\circ} \mathrm{C}$ to perform acid degradation, treated with $0.1 \mathrm{~N} \mathrm{NaOH}$ for $3 \mathrm{~h}$ at $80^{\circ} \mathrm{C}$ for base degradation, treated with $20 \%$ \& $30 \% \mathrm{H}_{2} \mathrm{O}_{2}$ for $3 \mathrm{~h}$ at $80^{\circ} \mathrm{C}$ for peroxide degradation. The standard drug solution was placed in oven at $105^{\circ} \mathrm{C}$ for $76 \mathrm{~h}$ to study dry heat degradation. Stress testing under neutral conditions was studied by refluxing the drug in water for $75 \mathrm{~h}$ at $60{ }^{\circ} \mathrm{C}$.

Before injecting the samples into system, they were neutralized and diluted to get $100 \mu \mathrm{g} / \mathrm{mL}$ of glecaprevir and $40 \mu \mathrm{g} / \mathrm{mL}$ for pibrentasvir.

\section{RESULTS AND DISCUSSION}

Defining quality target profile: It is a prospective summary of quality characteristics of a drug product taking into account together with the attributes affecting method performance (Table-1).
Selection of chromatographic conditions: The mobile phase employed was chromatographic separation were sodium phosphate monobasic and monohydric buffer and acetonitrile (65:35) having $\mathrm{pH}$ of 4.2 at $1 \mathrm{~mL} / \mathrm{min}$ flow rate. The column temperature was maintained at $30^{\circ} \mathrm{C}$ and detection was carried at $260 \mathrm{~nm}$. Retention time of glecaprevir and pibrentasvir were obtained at 2.638 min and 3.708 (Fig. 1).

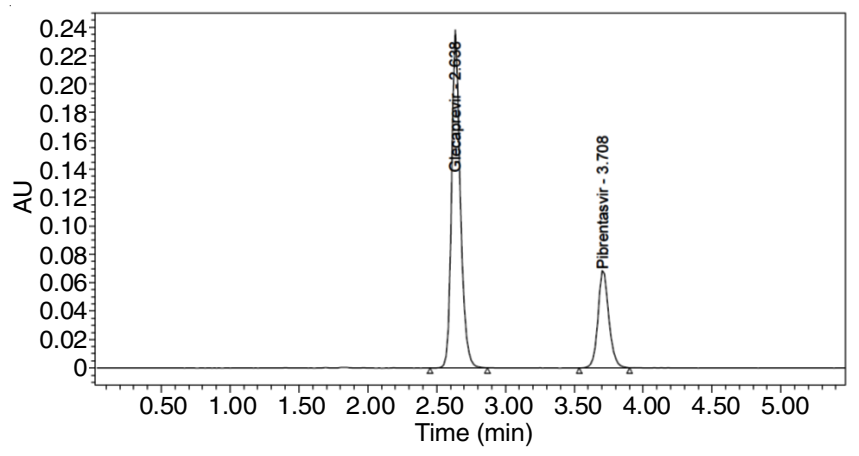

Fig. 1. Optimized chromatogram of glecaprevir and pibrentasvir

Forced degradation: Stress degradation studies of glecaprevir and pibrentasvir were carried out under hydrolysis (acid, base and neutral), oxidation, photolytic. The chromatograms of forced degradation studies were show in Fig. 2. The glecaprevir and pibrentasvir were stable under the stress condition of thermal, UV and water (Table-2). The drug was treated under acidic and Peroxide condition, its shows degradation with one degradant peak in each condition. But in alkali conditions it shows three degradant peaks (DP1, DP2, DP3). The DP1 and DP2 resolution were 2.1, which are more likely to co-elute.

So it is evident that the alkali condition has significant effect on the stability of glecaprevir and pibrentasvir than any other stress condition.

Risk assessment: Actually the degradant peaks formed in alkali degradation were eluted very closely. So the selectivity of the proposed method was affected by co-elution of these degradant peaks and drug peaks. The risk of co-elution was very high which may lead to method failure often encountered in stability indicating method.

Design of experiment: Based on the risk assessment the critical analytical attributes which shows effect on method performance were identified as mobile phase ratio, $\mathrm{pH}$ of mobile phase and column temperature. The method responses selected were Retention time of the drug and resolution between degradant peak 1 and degradant peak 2 which likely co-elute and

\begin{tabular}{|c|c|c|}
\hline \multicolumn{3}{|c|}{$\begin{array}{c}\text { TABLE-1 } \\
\text { QTPP FOR GLECAPREVIR AND PIBRENTASVIR }\end{array}$} \\
\hline QTTP element & Target & Justification \\
\hline \multicolumn{3}{|l|}{ Sample } \\
\hline Dosage form & API and degradation products & $\begin{array}{l}\text { Analytical method need to develop to assess the stability of the drug with } \\
\text { its degradation products. }\end{array}$ \\
\hline Appearance & White to half white & Available in solid form \\
\hline Impurity percentage & $0.09 \%$ & Critical \\
\hline \multicolumn{3}{|l|}{ Method } \\
\hline Method type & Reverse phase & $\begin{array}{l}\text { Used to get good retention time for moderate water soluble drug like } \\
\text { glecaprevir }(\log \text { p } 4.26) \& \text { pibrentasvir (solubility }<0.1 \mathrm{mg} / \mathrm{mL} \text { ) }\end{array}$ \\
\hline Instrument type & Binary pump & For effective mixing of solvent system \\
\hline Stability indicating assay & API and degradation products & To indicate the stability of product under various stress conditions \\
\hline
\end{tabular}




\begin{tabular}{cccc|cr}
\hline & \multicolumn{3}{c}{ TABLE-2 } \\
\multicolumn{2}{c}{ DEGRADATION PERCENTAGE OF GLECAPREVIR AND PIBRENTASVIR UNDER VARIOUS STRESS CONDITION } \\
\hline \multirow{2}{*}{ Condition } & \multirow{2}{*}{ Assay initial (\%) } & \multicolumn{2}{c}{ Glecaprevir } & \multicolumn{2}{c}{ Pibrentasvir } \\
\cline { 3 - 6 } & & Assay after degradation (\%) & Degradation (\%) & Assay after degradation (\%) & Degradation (\%) \\
\hline Acid & 100.00 & 65.06 & 34.94 & 65.13 & 34.87 \\
Base & 100.00 & 74.39 & 25.61 & 88.05 & 11.95 \\
Peroxide & 100.00 & 76.45 & 23.55 & 84.51 & 15.49 \\
Thermal & 100.00 & 95.46 & 4.54 & 96.37 & 3.63 \\
\hline
\end{tabular}
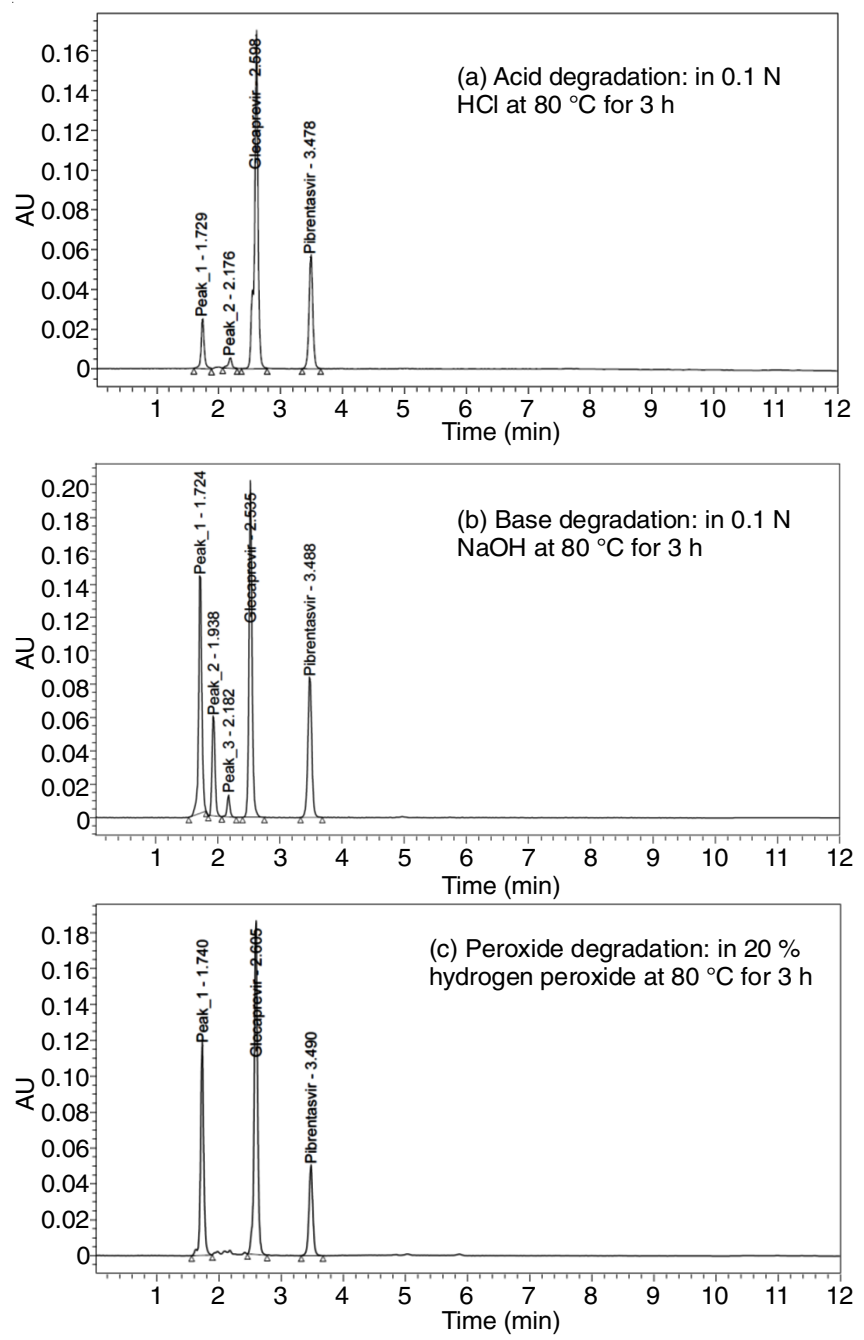

Fig. 2. Forced degradation chromatograms of glecaprevir and pibrentasvir

lead to method failure often. Preferably in response surface method, $2^{3}$ factorial designs were selected. The selected method responses and its levels were given in Table-3.

\begin{tabular}{lccc}
\multicolumn{5}{c}{ TABLE-3 } \\
\multicolumn{4}{c}{ DESIGN OF EXPERIMENTS-LEVELS OF VARIABLES } \\
\hline \multicolumn{1}{c}{ Variables } & Low level & Mid level & High level \\
& -1 level & 0 level & +1 level \\
\hline Mobile phase ratio $(\%)$ & 55.00 & 65.00 & 75.00 \\
pH mobile phase & 3.50 & 4.2 & 4.9 \\
Column temperature $\left({ }^{\circ} \mathrm{C}\right)$ & 27 & 30 & 33 \\
\hline
\end{tabular}

The central composite design was selected and 20 chromatogram runs were conducted as per DoE design and the method responses of each runs were mentioned in Table- 4 .

\section{Statistical analysis of method responses}

ANOVA for method response 1 - resolution: The analysis of variance (ANOVA) of regression parameters of the predicted response surface quadratic model for resolution was obtained from DoE software (Table-5). The Model F-value of 18.13 implies the model is significant. There is only $0.01 \%$ chance that a "Model F-Value" this large could occur due to noise. Values of "Prob > F" less than 0.0500 indicate model terms are significant. In this case $\mathrm{A}, \mathrm{C}, \mathrm{AC}, \mathrm{A}^{2}, \mathrm{~B}^{2}$ are significant model terms. Values greater than 0.1000 indicate the model terms are not significant. The "Lack of Fit F-value" of 4.91 implies that there is a $5.27 \%$ chance that a "Lack of Fit F-value" this large could occur due to noise. The "Pred R-Squared" of 0.6223 is closed to the "Adj R-Squared" of 0.8903 as one might normally expect. "Adeq Precision" measures the signal to noise ratio. A ratio greater than 4 is desirable. The model ratio of 15.372 indicates an adequate signal. This model can be used to navigate the design space.

The equation in terms of actual factors can be used to make predictions about the response of resolution and process variables by polynomial equation:

$$
\begin{gathered}
\text { Res }=-42.70331+5.43168 \mathrm{pH}+1.87400 \mathrm{TEM}+0.044293 \\
\% \mathrm{MP}-0.029762 \mathrm{pH} * \mathrm{TEM}+0.058929 \mathrm{pH} * \% \mathrm{MP}+ \\
4.16667 \mathrm{E}-004 \mathrm{TEM} * \% \mathrm{MP}-0.83982 \mathrm{pH} 2- \\
0.030010 \mathrm{TEM} 2-1.99380 \mathrm{E}-003 \% \mathrm{MP} 2
\end{gathered}
$$

3D and Contour graph for resolution: From ANOVA report on resolution, it is clearly states that interaction effect of $\mathrm{pH}$ and temperature has $\mathrm{p}$-value higher than 0.05 so interaction effect these terms doesn't have any significant effect on resolution. The interaction effect temperature and $\%$ mobile phase p-value also greater than 0.05 so interaction effect these terms doesn't have any significant effect on resolution.

The interaction effect of $\mathrm{pH}$ of mobile phase and $\%$ mobile phase ratio has significant effect on resolution. By keeping constant temperature at $30^{\circ} \mathrm{C}$, the interaction effect of $\mathrm{pH}$ of mobile phase and $\%$ mobile phase ratio were studied from contour and 3D graph. From the graph at lower $\mathrm{pH}$ and lower level of $\%$ mobile phase can give resolution lesser than 1. At higher $\mathrm{pH}$ and higher $\%$ mobile phase ratio can give resolution more than 2.8 (Fig. 3).

ANOVA for method response 2 - retention time of glecaprevir: The analysis of variance (ANOVA) of regression parameters of the predicted response surface quadratic model for retention time of glecaprevir was obtained from DoE software and given in Table-6. The Model F-value of 17.06 implies the model is significant. There is only a $0.01 \%$ chance that a "Model F-Value" this large could occur due to noise. Values of "Prob > F" less than 0.0500 indicate model terms are significant. In this case $\mathrm{A}, \mathrm{C}, \mathrm{A}^{2}, \mathrm{C}^{2}$ are significant model 


\begin{tabular}{|c|c|c|c|c|c|c|c|}
\hline \multicolumn{8}{|c|}{$\begin{array}{c}\text { TABLE-4 } \\
\text { CENTRAL COMPOSITE DESIGN FOR SCREENING OF METHOD PARAMETERS }\end{array}$} \\
\hline \multirow[t]{2}{*}{ Std. } & \multirow[t]{2}{*}{ Run } & $\begin{array}{c}\text { Factor } 1 \\
\text { A: } \mathrm{pH} \text { Mobile } \\
\text { Phase }\end{array}$ & Bactor 2 & $\begin{array}{c}\text { Factor } 3 \\
\text { C: mobile phase } \\
\text { ratio }\end{array}$ & $\begin{array}{l}\text { Response } 1 \\
\text { Resolution }\end{array}$ & $\begin{array}{l}\text { Response } 2 \\
t_{R} \text { of GLEC }\end{array}$ & $\begin{array}{l}\text { Response } 2 \\
t_{R} \text { of PIBRE }\end{array}$ \\
\hline & & - & ${ }^{\circ} \mathrm{C}$ & $\%$ & Number & Time $(\min )$ & Time $(\mathrm{min})$ \\
\hline 4 & 1 & & 33 & 55 & 1.2 & 2.199 & 2.683 \\
\hline 6 & 2 & 4.9 & 27 & 75 & 3.1 & 2.939 & 5.204 \\
\hline 17 & 3 & 4.2 & 30 & 65 & 2.2 & 2.492 & 3.511 \\
\hline 8 & 4 & 4.9 & 33 & 75 & 2.9 & 2.953 & 5.342 \\
\hline 3 & 5 & 3.5 & 33 & 55 & 0 & 2.04 & 2.648 \\
\hline 16 & 6 & 4.2 & 30 & 65 & 2.1 & 2.492 & 3.617 \\
\hline 14 & 7 & 4.2 & 30 & 81.81793 & 2.6 & 3.569 & 7.114 \\
\hline 15 & 8 & 4.2 & 30 & 65 & 2.2 & 2.487 & 3.695 \\
\hline 1 & 9 & 3.5 & 27 & 55 & 0 & 2.052 & 2.675 \\
\hline 13 & 10 & 4.2 & 30 & 48.18207 & 0.9 & 2.104 & 2.465 \\
\hline 5 & 11 & 3.5 & 27 & 75 & 0 & 2.658 & 3.955 \\
\hline 9 & 12 & 3.022745 & 30 & 65 & 0 & 2.028 & 3.329 \\
\hline 18 & 13 & 4.2 & 30 & 65 & 1.7 & 2.274 & 3.214 \\
\hline 20 & 14 & 4.2 & 30 & 65 & 2.2 & 2.484 & 3.486 \\
\hline 2 & 15 & 4.9 & 27 & 55 & 1.5 & 2.206 & 2.689 \\
\hline 12 & 16 & 4.2 & 35.04538 & 65 & 1.4 & 2.467 & 3.463 \\
\hline 19 & 17 & 4.2 & 30 & 65 & 2.2 & 2.496 & 3.594 \\
\hline 10 & 18 & 5.377255 & 30 & 65 & 2.3 & 2.386 & 3.414 \\
\hline 7 & 19 & 3.5 & 33 & 75 & 0 & 2.312 & 5.272 \\
\hline 11 & 20 & 4.2 & 24.95462 & 65 & 1.7 & 2.512 & 3.585 \\
\hline
\end{tabular}

TABLE-5

ANOVA FOR QUADRATIC MODEL FOR METHOD RESPONSE 1-RESOLUTION

\begin{tabular}{|c|c|c|c|c|c|c|}
\hline Source & Sum of squares & $\mathrm{df}$ & Mean square & F-value & p-value & \\
\hline Model & 19.29542 & 9 & 2.143936 & 18.12935 & $<0.0001$ & Significant \\
\hline A-pH & 11.56619 & 1 & 11.56619 & 97.80492 & $<0.0001$ & \\
\hline B-TEM & 0.073889 & 1 & 0.073889 & 0.624816 & 0.4476 & \\
\hline C-\%MP & 2.777643 & 1 & 2.777643 & 23.48805 & 0.0007 & \\
\hline $\mathrm{AB}$ & 0.03125 & 1 & 0.03125 & 0.264253 & 0.6184 & \\
\hline $\mathrm{AC}$ & 1.36125 & 1 & 1.36125 & 11.51088 & 0.0069 & \\
\hline $\mathrm{BC}$ & 0.00125 & 1 & 0.00125 & 0.01057 & 0.9201 & \\
\hline $\mathrm{A}^{2}$ & 2.440442 & 1 & 2.440442 & 20.63664 & 0.0011 & \\
\hline $\mathrm{B}^{2}$ & 1.051291 & 1 & 1.051291 & 8.889828 & 0.0138 & \\
\hline $\mathrm{C}^{2}$ & 0.572885 & 1 & 0.572885 & 4.844374 & 0.0524 & \\
\hline Residual & 1.182577 & 10 & 0.118258 & & & \\
\hline Lack of Fit & 0.982577 & 5 & 0.196515 & 4.912886 & 0.0527 & Not significant \\
\hline Pure Error & 0.2 & 5 & 0.04 & & & \\
\hline Cor Total & 20.478 & 19 & & & & \\
\hline \multicolumn{7}{|c|}{ Summary of quadratic model } \\
\hline \multirow{2}{*}{$\begin{array}{c}\text { Std. Dev. } \\
\mathrm{R}^{2}\end{array}$} & 0.343886 & & \multirow{2}{*}{\multicolumn{2}{|c|}{$\begin{array}{c}7.73367 \\
0.890278\end{array}$}} & Adequate precision & 15.37228 \\
\hline & 0.942251 & & & & Predicted $\mathrm{R}^{2}$ & 0.622342 \\
\hline
\end{tabular}

terms. Values greater than 0.1000 indicate the model terms are not significant. The "Lack of Fit F-value" of 3.07 implies the Lack of Fit is not significant relative to the pure error. There is a $12.18 \%$ chance that a "Lack of Fit F-value" this large could occur due to noise. Non-significant lack of fit is good - we want the model to fit.The "Pred R-Squared" of 0.6191 is as close to the "Adj R-Squared" of 0.8838 as one might normally expect. "Adeq Precision" measures the signal to noise ratio. A ratio greater than 4 is desirable, ratio of 16.270 indicates an adequate signal. This model can be used to navigate the deign space.

The equation in terms of actual factors can be used to make predictions about the response of retention time of glecaprevir and process variables by polynomial equation:
Rt-GLEC $=+3.08462+0.67368 \mathrm{pH}+0.032872$ TEM$0.12098 \% \mathrm{MP}+0.021726 \mathrm{pH} * \mathrm{TEM}+0.010875 \mathrm{pH} *$

$\%$ MP-1.30417E-003TEM * \% MP -0.21907pH28.29429E-004 TEM2 + 1.15218E-003\% MP2

3D and Contour graph for retention time of glecaprevir: From ANOVA report on retention time of glecaprevir, it clearly states that the interaction effect of $\mathrm{pH}$ and temperature, temperature and \% mobile phase has $\mathrm{p}$-value higher than 0.05 so interaction effect these terms doesn't have any significant effect on retention time of glecaprevir.

The interaction effect of $\mathrm{pH}$ of mobile phase and $\%$ mobile phase ratio has also very little significant effect on retention time of glecaprevir. By keeping constant temperature at $30{ }^{\circ} \mathrm{C}$, the interaction effect of $\mathrm{pH}$ of mobile phase and $\%$ mobile 


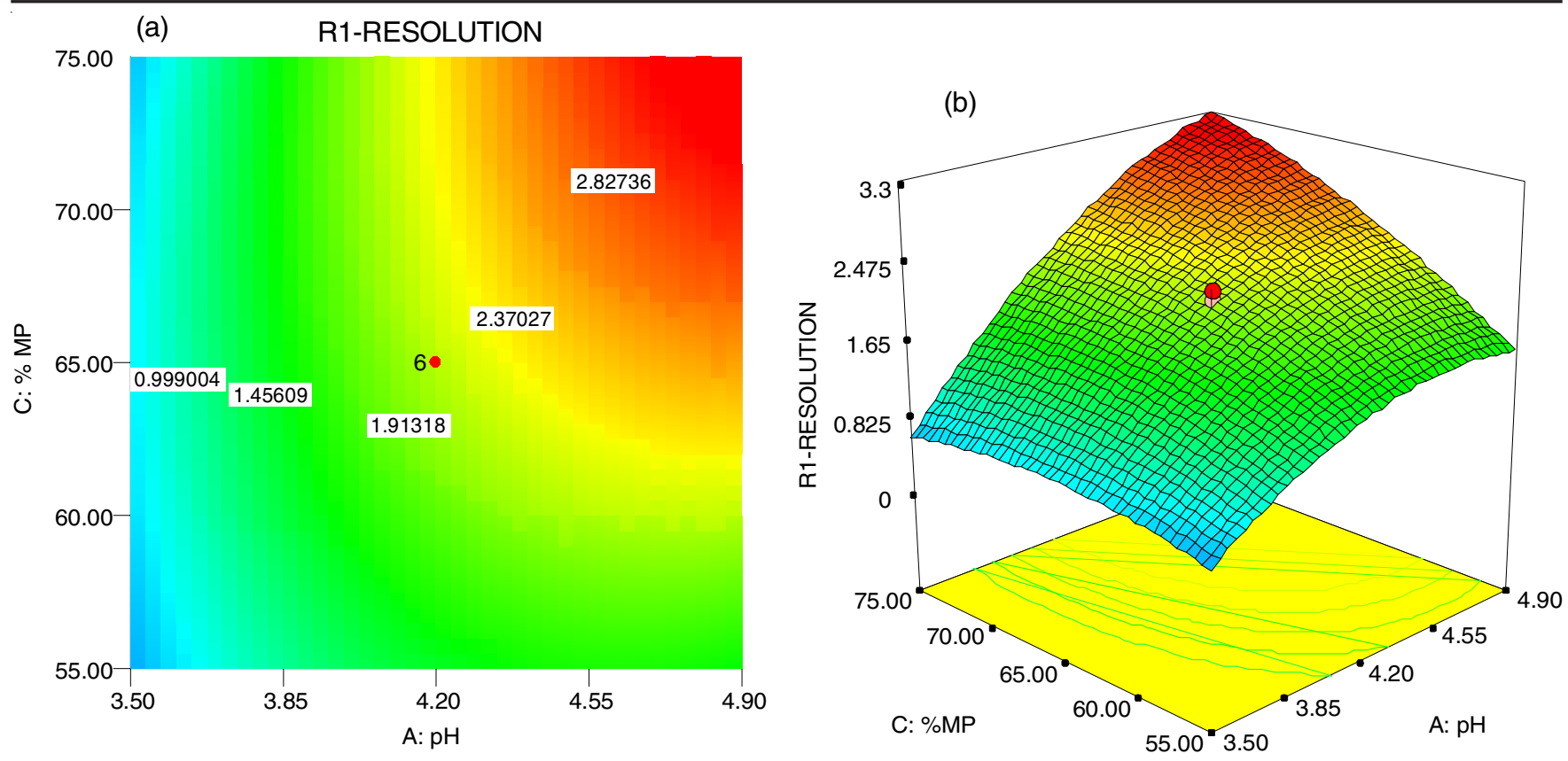

Fig. 3. (a) Contour plots and (b) response surface for resolution as a function of $\mathrm{pH}$ of mobile phase and $\%$ mobile phase ratio (constant temperature $30^{\circ} \mathrm{C}$ )

TABLE-6

ANOVA FOR QUADRATIC MODEL FOR METHOD RESPONSE 2 - RETENTION TIME OF GLECAPREVIR

\begin{tabular}{|c|c|c|c|c|c|c|}
\hline Source & Sum of squares & df & Mean square & F-value & p-value & \\
\hline Model & 2.440756 & 9 & 0.271195 & 17.0635 & $<0.0001$ & Significant \\
\hline A-pH & 0.247119 & 1 & 0.247119 & 15.54865 & 0.0028 & \\
\hline B-TEM & 0.013331 & 1 & 0.013331 & 0.838767 & 0.3813 & \\
\hline C-\%MP & 1.707389 & 1 & 1.707389 & 107.4283 & $<0.0001$ & \\
\hline $\mathrm{AB}$ & 0.016653 & 1 & 0.016653 & 1.047809 & 0.3301 & \\
\hline $\mathrm{AC}$ & 0.04636 & 1 & 0.04636 & 2.916962 & 0.1185 & \\
\hline $\mathrm{BC}$ & 0.012246 & 1 & 0.012246 & 0.770522 & 0.4007 & \\
\hline$A^{2}$ & 0.166057 & 1 & 0.166057 & 10.44822 & 0.0090 & \\
\hline $\mathrm{B}^{2}$ & 0.000803 & 1 & 0.000803 & 0.050528 & 0.8267 & \\
\hline $\mathrm{C}^{2}$ & 0.191313 & 1 & 0.191313 & 12.03735 & 0.0060 & \\
\hline Residual & 0.158933 & 10 & 0.015893 & & & \\
\hline Lack of Fit & 0.119892 & 5 & 0.023978 & 3.07094 & 0.1218 & Not significant \\
\hline Pure Error & 0.039041 & 5 & 0.007808 & & & \\
\hline Cor Total & 2.599689 & 19 & 0.271195 & & & \\
\hline \multicolumn{7}{|c|}{ Summary of quadratic model } \\
\hline Std. Dev. & 0.13 & & & 0.99 & Adequate precision & 16.270 \\
\hline $\mathrm{R}^{2}$ & 0.9389 & & & 0.8838 & Predicted $\mathrm{R}^{2}$ & 0.6191 \\
\hline
\end{tabular}

phase ratio were studied from contour and 3D graph (Fig. 4). From 65 to $55 \%$ of mobile phase ratio and $\mathrm{pH} 3.7$ to 4.9 gives the retention time less than $2.3 \mathrm{~min}$. at higher level of $\mathrm{pH}$ and mobile phase ration gives the rise in retention time of glecaprevir.

ANOVA for method response 3 - retention time of pibrentasvir: The analysis of variance (ANOVA) of regression parameters of the predicted response surface quadratic model for retention time of pibrentasvir was obtained from DoE software and given in Table-7. The Model F-value of 35.01 implies the model is significant. There is only $0.01 \%$ chance that a "Model F-Value" this large could occur due to noise. Values of "Prob > F" less than 0.0500 indicate model terms are significant. In this case $\mathrm{C}, \mathrm{C}^{2}$ are significant model terms. Values greater than 0.1000 indicate the model terms are not significant. The "Lack of Fit F-value" of 4.58 implies there is a $6.02 \%$ chance that a "Lack of Fit F-value" this large could occur due to noise. The "Pred R-Squared" of 0.7892 is in reasonable agreement with the "Adj R-Squared" of 0.9415."Adeq Precision" measures the signal to noise ratio. A ratio greater than 4 is desirable, ratio of 22.652 indicates an adequate signal. This model can be used to navigate the design space.

The equation in terms of actual factors can be used to make predictions about the response of retention time of pibrentasvir and process variables by polynomial equation.

$$
\begin{gathered}
\text { Rt-PIB }=+16.65814+2.04414 \mathrm{pH}+0.059328 \mathrm{TEM}- \\
0.71127 \% \mathrm{MP}-0.068929 \mathrm{pH} * \mathrm{TEM}+0.022679 \mathrm{pH} * \\
\% \mathrm{MP}+6.20000 \mathrm{E}-003 \mathrm{TEM} * \% \mathrm{MP}-0.15385 \mathrm{pH} 2- \\
2.38547 \mathrm{E}-003 \mathrm{TEM} 2+4.25953 \mathrm{E}-003 \% \mathrm{MP} 2
\end{gathered}
$$

3D and Contour graph for retention time: From ANOVA report on retention time of pibrentasvir clearly states that 


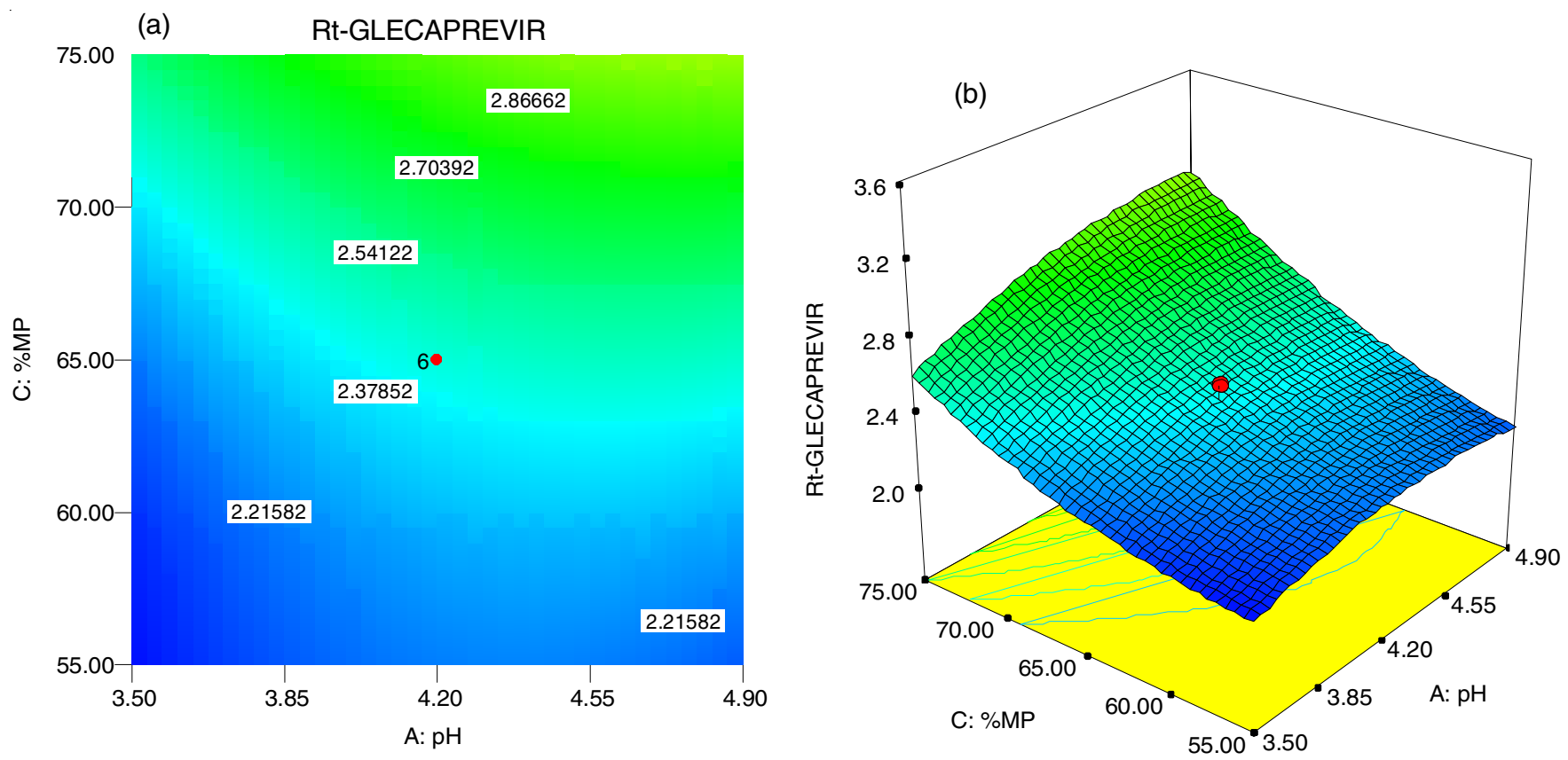

Fig. 4. (a) Contour plots and (b) response surface for retention time of glecaprevir as a function of pH of mobile phase and $\%$ mobile phase ratio (constant temperature $30^{\circ} \mathrm{C}$ )

TABLE-7

ANOVA FOR QUADRATIC MODEL FOR RESPONSE 3 - RETENTION TIME OF PIBRENTASVIR

\begin{tabular}{|c|c|c|c|c|c|c|}
\hline Source & Sum of squares & df & Mean square & F-value & $\mathrm{p}$-value & \\
\hline Model & 24.68433 & 9 & 2.742704 & 35.00541 & $<0.0001$ & Significant \\
\hline A-pH & 0.167167 & 1 & 0.167167 & 2.133571 & 0.1748 & \\
\hline B-TEM & 0.108418 & 1 & 0.108418 & 1.383755 & 0.2667 & \\
\hline C-\%MP & 20.90503 & 1 & 20.90503 & 266.813 & $<0.0001$ & \\
\hline $\mathrm{AB}$ & 0.167621 & 1 & 0.167621 & 2.139358 & 0.1743 & \\
\hline $\mathrm{AC}$ & 0.201613 & 1 & 0.201613 & 2.573201 & 0.1398 & \\
\hline $\mathrm{BC}$ & 0.276768 & 1 & 0.276768 & 3.532418 & 0.0896 & \\
\hline $\mathrm{A}^{2}$ & 0.0819 & 1 & 0.0819 & 1.045304 & 0.3307 & \\
\hline $\mathrm{B}^{2}$ & 0.006643 & 1 & 0.006643 & 0.08478 & 0.7769 & \\
\hline $\mathrm{C}^{2}$ & 2.614721 & 1 & 2.614721 & 33.37195 & 0.0002 & \\
\hline Residual & 0.783509 & 10 & 0.078351 & & & \\
\hline Lack of Fit & 0.643127 & 5 & 0.128625 & 4.581281 & 0.0602 & Not significan \\
\hline Pure Error & 0.140382 & 5 & 0.028076 & & & \\
\hline Cor Total & 25.46784 & 19 & & & & \\
\hline \multicolumn{7}{|c|}{ Summary of quadratic model } \\
\hline Std. Dev. & 0.28 & & & 5.37 & Adequate precision & 22.652 \\
\hline $\mathrm{R}^{2}$ & 0.9692 & & & 0.9415 & Predicted $\mathrm{R}^{2}$ & 0.7892 \\
\hline
\end{tabular}

interaction effect of $\mathrm{pH}$ and temperature has $\mathrm{p}$-value higher than 0.05 so interaction effect these terms doesn't have any significant effect on retention time of pibrentasvir. The interaction effect temperature and \% mobile phase p-value also greater than 0.05 , also don't have any significant effect on resolution. The interaction effect of $\mathrm{pH}$ of mobile phase and \% mobile phase ratio has little significant effect on retention time of pibrentasvir. By keeping constant temperature at $30^{\circ} \mathrm{C}$, the interaction effect of $\mathrm{pH}$ of mobile phase and \% mobile phase ratio were studied from contour and 3D graph (Fig. 5). Lower than $65 \%$ mobile phase ratio at given temperature range gives low retention time of pibrentasvir. Above $65 \%$ to $75 \%$ of mobile phase ratio and 30 to $33{ }^{\circ} \mathrm{C}$ of column temperature give the retention time of pibrentasvir above 4.0 to $4.9 \mathrm{~min}$.

Method optimization through DoE software: The accuracy of the model was evaluated by numerical optimization method by the design expert software. The desired goals for method response resolution was kept at maximum 3.1 and retention time of glecaprevir (2.028-3.569 min) and pibrentasvir (2.465-7.114 $\mathrm{min}$ ) were kept in range. The chromatographic conditions suggested by design expert were $\mathrm{pH} 4.85$, temperature at $28{ }^{\circ} \mathrm{C}$ and $\%$ mobile phase ratio at 73.15 with desirability 1 . At these conditions the predicted method responses calculated by the model for resolution was 3.11, retention time of glecaprevir was $2.922 \mathrm{~min}$ and retention time of pibrentasvir was at 4.8909 min. The same experimental conditions were maintained and run the HPLC system. The optimized chromatogram of alkali degraded glecaprevir and pibrentasvir were obtained and it produced satisfactory system suitability parameters. This revealed that all the responses were within the statistical limit of $95 \%$ confidence intervals leading to high degree of closeness of the predicted data with the observed ones. 

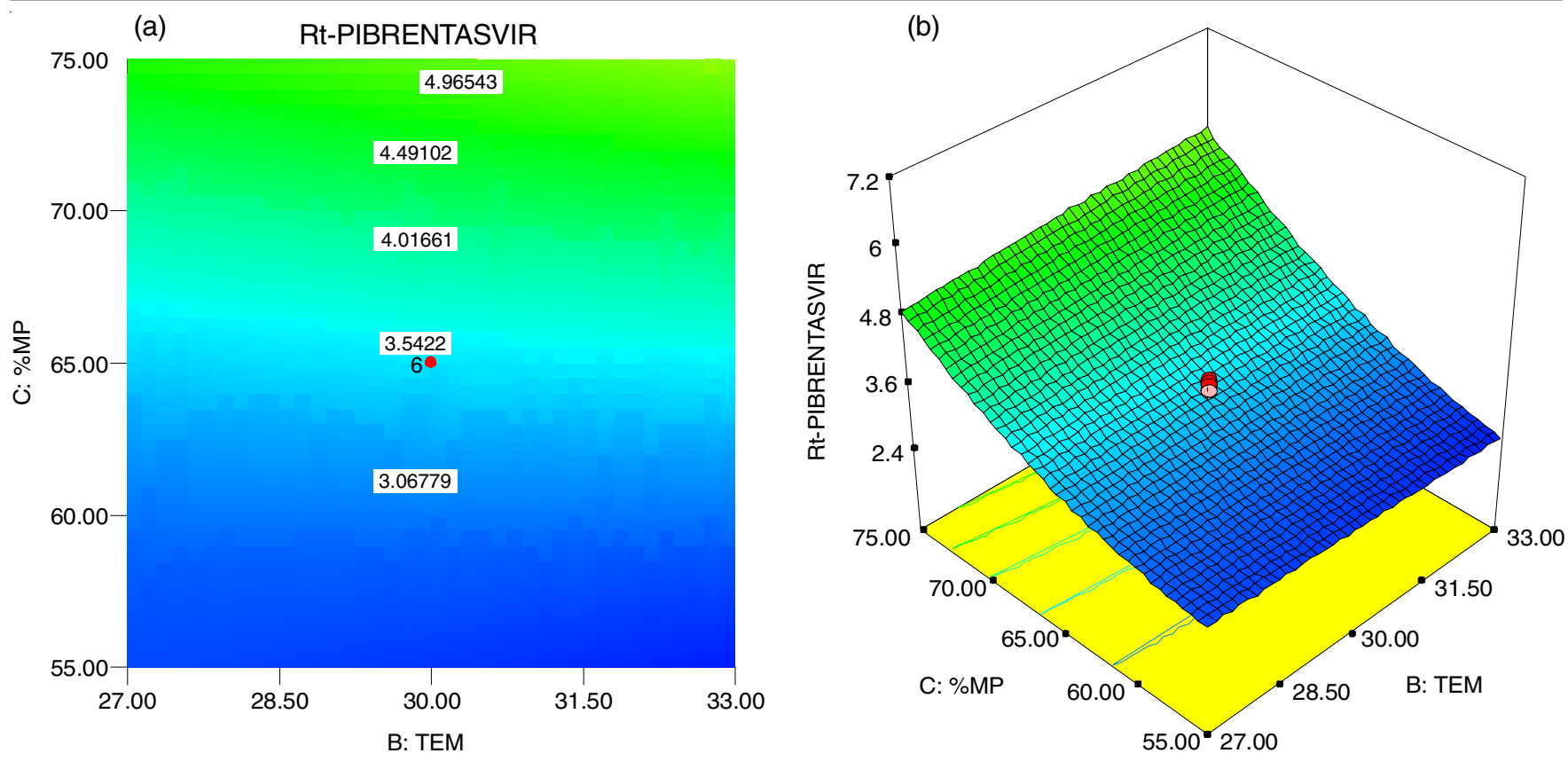

Fig. 5. Contour plots (a) and response surface (b) for retention time of pibrentasvir as a function of temperature and $\%$ mobile phase ratio (constant $\mathrm{pH}$ of mobile phase 4.20)

\begin{tabular}{lcccc}
\multicolumn{5}{c}{ TABLE-8 } \\
& \multicolumn{5}{c}{ VERIFICATION OF EXPERIMENT AT OPTIMUM CONDITIONS } \\
\hline \multicolumn{1}{c}{ Method response } & Prediction & $95 \%$ CI low & $95 \%$ CI high & Observed \\
\hline Resolution & 3.119 & 2.66 & 3.58 & 3.100 \\
Retention time of glecaprevir & 2.92 & 2.75 & 3.09 & 2.936 \\
Retention time of pibrentasvir & 4.89 & 4.52 & 5.26 & 4.889 \\
\hline
\end{tabular}

The verification data of predicted values by the model and observed values were given in the Table- 8 .

\section{Conclusion}

A simple, selective and robust stability indicating RPHPLC method was developed for the estimation of glecaprevir and pibrentasvir in bulk drug through the application of quality by design approach. $\mathrm{QbD}$ approach helps us to understand the influencing parameters and its effect on method responses along with risk assessment. Interaction among all the variables was investigated by employing response surface full factorial central composite design. The significant effects of individual factor, interaction effect between the variables on individual method responses were studied. The optimal setting of chromatographic conditions was in the analytical design space using desirability function was obtained. The demonstrated high predictability model can use for the estimation of glecaprevir and pibrentasvir routine analysis.

\section{ACKNOWLEDGEMENTS}

One of the authors (C. Vanitha) thanks Sri Venkateswara College of Pharmacy, RVS Nagar, Chittoor, India for providing research facilities for completion of this research work.

\section{CONFLICT OF INTEREST}

The authors declare that there is no conflict of interests regarding the publication of this article.

\section{REFERENCES}

1. H. Hubbard and E. Lawitz, Expert Rev. Gastroenterol. Hepatol., 12, 9 (2018); https://doi.org/10.1080/17474124.2018.1411802.

2. P.Y. Kwo, F. Poordad, A. Asatryan, S. Wang, D.L. Wyles, T. Hassanein, F. Felizarta, M.S. Sulkowski, E. Gane, B. Maliakkal, J.S. Overcash, S.C. Gordon, A.J. Muir, H. Aguilar, K. Agarwal, G.J. Dore, C.-W. Lin, R. Liu, S.S. Lovell, T.I. Ng, J. Kort and F.J. Mensa, J. Hepatol., 67, 263 (2017); https://doi.org/10.1016/j.jhep.2017.03.039.

3. D.C. Babu, C.M. Chetty and M. SK. Mastanamma, Pharm. Methods, 9, 79 (2018);

https://doi.org/10.5530/phm.2018.2.14.

4. Md. Abdul Sattar and A. Suneetha, Int. J. Res. Pharm. Life Sci., 6, 25 (2018).

5. K. Hemalatha, C. Kistayya, N.D. Nizamuddhin and D. Dastiagiriamma, Innovat. Int. J. Med.Pharm. Sci., 3, 5 (2018).

6. M. Sridevia, T.S. Rao and C.G. Naidu, Eur. J. Biomed. Pharm. Sci., 5, 473 (2018).

7. Y.N. Reddy, J. Sreeramulu and B. Balaswami, Res. J. Pharm. Technol., 12, 625 (2019); https://doi.org/10.5958/0974-360X.2019.00111.2.

8. V. Sreeram and Ch.Venkateswarlu, J. Pharm. Sci. Res., 10, 2757 (2018).

9. ICH Q8 Quality Guidance: Pharmaceutical Development.

10. S. Beg, G. Sharma, O.P. Katare, S. Lohan and B. Singh, J. Chromatogr. Sci., 53, 1048 (2015);

https://doi.org/10.1093/chromsci/bmu165.

11. N.K. Yadav, A. Raghuvanshi, G. Sharma, S. Beg, O.P. Katare and S. Nanda, J. Chromatogr. Sci., 54, 377 (2016); https://doi.org/10.1093/chromsci/bmv151.

12. ICH Guideline, Validation of Analytical Procedures: Text and Methodology Q2 (R1), International Conference on Harmonization: Geneva, Switzerland (2005).

13. ICH Guideline, Stability Testing of New Drug Substances and Products Q1A (R2), International Conference on Harmonization: Geneva, Switzerland (2003). 